\title{
La investigación y la creación son tu energía, el tema lo pones tú
}

\section{Pedro Pablo Gómez Moreno}

Universidad Distrital Francisco José de Caldas

Editor

ppgomezm@udistrital.edu.co

$-$

Cómo citar este artículo: Gómez, Pedro Pablo (2018). La investigación y la creación son tu energía, el tema lo pones tú. Calle14: revista de investigación en el campo del arte, 13 (22) pp 10-15. DOI: https://doi. org/10.14483/21450706.12985 
Muy seguramente nuestros lectores podrían pensar, de entrada, que el título de este editorial es la paráfrasis de un comercial. Y cómo no, lo es de un conocido producto con sabor a chocolate que promete darnos la energía necesaria para alcanzar la meta que nos propongamos.

Pero lo que pretendemos aquí, antes que persuadir a nuestros lectores (muchos de ellos investigadores y creadores que han elegido a Calle14 como un medio adecuado para la socialización de sus resultados de investigación y creación) es dar cuenta de algunos de los ajustes editoriales que estamos implementando en esta segunda década de la revista, como lo anunciamos en esta misma sección en el número anterior. Entre los mencionados ajustes se encuentran los siguientes: el cambio del carácter temático de la sección central de la revista, las consecuentes presiones en las demás secciones que componen nuestra publicación y la actualización de la guía para autores, con otros que serán evidentes al leer el número que el lector tiene en sus manos.

En 2007, el Comité Editorial de la joven revista estimó conveniente la idea de promover, cada año, un tema relevante para el campo del arte, con el propósito de insertarse en los debates más importantes del arte y la cultura contemporáneos. Y así fue. Iniciamos con el problema del autor y la autoría (2007), seguido por el museo y lo museal (2008), arte y cultura (2009-2010), arte y decolonialidad (2010-2011), la cuestión estética y las estéticas en cuestión (2011-2012), arte, ciudadanías y universidad (2012-2013), arte y pedagogía (2013-2014), arte y manifestaciones populares (2015), arte y memoria (2015 y 2016), arte y conflicto (2016-2017).

El autor invitado, que ha sido otra política de Calle14, también se pensaba en términos de la temática relevante de cada año. Durante una década vimos los efectos positivos de los temas propuestos, que nos permitieron el acceso a especialistas de cada uno de los campos del conocimiento enfocados por nuestros temas y problemas. Pero al mismo tiempo, nos dimos cuenta que privilegiar un tema sobre otros tiene un elemento de riesgo y arbitrariedad que se hace evidente en el carácter desigual de la respuesta de los autores a los temas propuestos. Además, como consecuencia, los artículos aprobados cuyos temas no tenían que ver directamente con la sección central y temática de la revista, sufrían un retraso en su agenda de publicación en las secciones más pequeñas. Por lo anterior, y sin desconocer el carácter positivo que tiene el promover temas de debate desde las revistas especializadas, al inicio de un nuevo ciclo decenal de Calle14 hemos decidido que la revista convocará, de manera permanente, el envío de artículos resultado de investigación, creación e investigación-creación que aborden los temas y problemas que los investigadores y creadores 
se hayan propuesto de acuerdo con sus intereses de largo aliento, y no por atender a una determinada convocatoria temática. Los diversos temas conformarán una sección central de Calle14 más variada e inter-epistémica.

De acuerdo con lo anterior, las actuales secciones de Calle14 pretenden dar cuenta de la estructura de una revista de investigación que afirma el arte como el lugar principal desde donde se realizan y piensan sus textos, se ubican sus debates y pretensiones de transformación social:

- Editorial: escrito por el editor, por un invitado, o por uno o varios miembros del Comité Editorial/Científico.

- Sección Central: está constituida por los artículos de investigación, reflexión y revisión que sean aprobados para cada número, incluyendo el artículo de un autor invitado.

- Expresiones Emergentes: es un espacio para jóvenes investigadores y creadores.

- Pensamiento Sensible: propuestas relevantes de artistas y creadores que sean consistentes con el enfoque de la revista.

- Textualidades Otras: en esta sección se presentan, de manera no permanente, artículos del siguiente tipo: artículo corto, reporte de caso, revisión de tema, cartas al editor, traducción, documento de reflexión no derivado de investigación, reseña bibliográfica y otros.

El tercer aspecto tiene que ver con la actualización de la guía para autores.

Recomendamos encarecidamente a los autores, antes de hacer sus envíos, leer atentamente esta guía, porque en ella se consignan, entre otros aspectos, las normas de la revista, su carácter, periodicidad, estructura, el tipo de artículos aceptados, su forma de presentación y los criterios de evaluación. De la misma manera, la guía para autores establece la forma en que la revista reconoce los derechos de autor y su política de acceso a los contenidos de la publicación. Otros aspectos relevantes de la guía son la política de buenas prácticas, la declaración de privacidad de los datos de los autores, evaluadores y suscriptores. Y finalmente, la aceptación de las condiciones expresadas en la guía por parte de los autores que realicen sus envíos tiene gran importancia para evitar posibles conflictos y hacer posible una publicación de acceso abierto y sin fines de lucro en este medio institucional.

No sobra recordar a los autores que, sin excepción, los artículos deben enviarse a través de la plataforma OJS de la revista Calle14: (http://revistas.udistrital.edu.co/ 
ojs/index.php/c14) realizando el correspondiente registro del autor. De esta manera, será posible para los autores hacer el seguimiento al proceso de evaluación y edición de sus artículos. No se considerarán artículos incompletos o que no cumplan con las normas establecidas (Véase Guía para autores, VIII. Sobre el envío de los artículos). Pues bien, no nos queda más que invitar a nuestros lectores a un nuevo viaje por la investigación y la creación artística, que inicia con el artículo de pensamiento visual del artista John Castles, seguido por una exploración de obras musicales referentes a la guitarra eléctrica en Colombia y otra que trata sobre los imaginarios sociales que se tejen alrededor de las bandas pelayeras del departamento de Córdoba. Luego, se indaga por la evocación de la memoria de África que está presente en algunas de las obras del arquitecto colombiano Rogelio Salmona, para enseguida centrarnos en la diversidad de imágenes e imaginarios de la ciudad de Tunja y detenernos en los retos que representa la reapertura del Museo Nacional de Telecomunicaciones de Colombia (MNT). Más adelante, encontraremos una aproximación a la pintura contemporánea que busca entender las condiciones de recepción que determinadas obras plantean al espectador y veremos, además, cómo el concepto de "imagen barroca" fue clave en la política cultural colonizadora que se instauró en el siglo XVIII en México. Siguiendo con categorías claves, podremos indagar cómo el concepto de heterogeneidad de E. Laclau puede ser clave para la lectura de creaciones culturales contemporáneas. Asimismo, podremos leer en qué consiste el arte de andar en la naturaleza, sus bases filosóficas e implicaciones éticas y políticas. Enseguida, encontramos un artículo que indaga por la relación entre los procesos artísticos y los procesos creativos que se realizan en la infancia; finalmente, se indaga por las condiciones necesarias para mantener la tradición alfarera en tres corregimientos del municipio de Valledupar. La sección central de la revista se cierra inquiriendo por las herramientas teóricas necesarias para la descolonización de la interpretación literaria, más allá de una cierta estereotipación de lo "afro" centrada en la obra de Antonio Preciado.

Claro está, estimado lector, que, así como los problemas de investigación los ponen los autores, en Calle14 el orden de la lectura lo pones tú.

Referencias

Araque Osorio, C. (2014). Arte y pedagogía. Calle 14 revista de investigación en el campo del arte, 8(11), 8-13. doi: https://doi.org/10.14483/udistrital.jour.c14.2013.2.a01 
(2014). ¿Arte y política o política en el arte? Calle 14 revista de investigación en el campo del arte, 9(14), 6-9. doi: https://doi.org/10.14483/udistrital.jour.

c14.2014.2.a01

(2012). Editorial la cuestión estética y las estéticas en cuestión. Calle 14 revista de investigación en el campo del arte, 6(8), 4-7. doi: https://doi.org/10.14483/ udistrital.jour.c14.2012.1.a01

(2014a). Arte y pedagogía. Calle 14 revista de investigación en el campo del arte, 8(12), 8-10. doi: https://doi.org/10.14483/udistrital.jour.c14.2014.1.a01

Arcos-Palma, R. (2011). Superando fronteras del saber. Calle 14 revista de investigación en el campo del arte, 5(6), 8-9. doi:https://doi.org/10.14483/udistrital. jour.c14.2011.1.a01

Cáceres, J. (2013). Arte, ciudad, universidad. Calle 14 revista de investigación en el campo del arte, 7(9), 6-8. doi: https://doi.org/10.14483/udistrital.jour.c14.2012.2.a01

Cortés, L., \& Gómez, P. (2011). El autor y la autoría. Calle 14 revista de investigación en el campo del arte, 1(1), 5. doi: https://doi.org/10.14483/21450706.1174

Gómez, P. (2017). Calle14: una década de mediación entre creadores, investigadores y comunidades del Sur Global. Calle 14 revista de investigación en el campo del arte, O(22), 170-173. doi: https://doi.org/10.14483/21450706.12811

(2011). Calle14 y su enfoque político-académico como medio de circulación de saberes y conocimientos. Calle 14 revista de investigación en el campo del arte, 4(5), 8-9. doi: https://doi.org/10.14483/21450706.1199

(2011). Interpelando al binomio arte-cultura. Calle 14 revista de investigación en el campo del arte, 4(4), 8-9. doi: https://doi.org/10.14483/21450706.1223

(2011). El museo y lo museal. Calle 14 revista de investigación en el campo

del arte, 2(2), 8-9. doi: https://doi.org/10.14483/21450706.1235 
(2011). Un "presente" y una invitación sin sobre de manila. Calle 14 revista de investigación en el campo del arte, 5(7), 7-8. doi: https://doi.org/10.14483/udistrital. jour.c14.2011.2.a01

Méndez, R. (2016). Sobre invenciones y truculencias. Calle 14 revista de investigación en el campo del arte, 11(18), 10-13. doi: https://doi.org/10.14483/udistrital.jour. c14.2016.1.a01

(2013). Editorial ciudad, universidad y arte. Calle 14 revista de investigación en el campo del arte, 7(10), 4-13. doi: https://doi.org/10.14483/udistrital.jour. c14.2013.1.a01

Muñoz Gómez, J. (2017). Arte, conflicto, solución. Calle 14 revista de investigación en el campo del arte, 12(21), 1-12. doi: https://doi.org/10.14483/21450706.12507

Niño Morales., S. (2017). El arte y la cultura en el post- acuerdo: respuesta y potencialidad. Calle 14 revista de investigación en el campo del arte, 11(20), 1-13. doi: https://doi.org/10.14483/udistrital.jour.c14.2016.3.a01

Ramírez Triana, C. (2016). EL ARTE DEL CONFLICTO. Calle 14 revista de investigación en el campo del arte, 11(19). doi: https://doi.org/10.14483/21450706.11082

Triana, C. (2016). Del arte y la memoria. Calle 14 revista de investigación en el campo del arte, 10(17), 10-13. doi: https://doi.org/10.14483/udistrital.jour.c14.2015.3.a01

(2015). Arte y manifestaciones populares en el contexto de la reforma.

Calle 14 revista de investigación en el campo del arte, 10(16), 10-13. doi: https://doi. org/10.14483/udistrital.jour.c14.2015.2.a01

(2015a). Investigación y carnaval en tiempos de reforma. Calle 14 revista de investigación en el campo del arte, 10(15), 9-13. doi: https://doi.org/10.14483/ udistrital.jour.c14.2015.1.a01

Walsh, C. (2011). ¿Qué es arte y cultura? Calle 14 revista de investigación en el campo del arte, 3(3), 8-9. doi: https://doi.org/10.14483/21450706.1211 